\title{
Hemicrania continua: clinical review, diagnosis and management
}

This article was published in the following Dove Press journal:

Journal of Pain Research

29 June 2017

Number of times this article has been viewed

\author{
Sanjay Prakash' \\ Payal Patel ${ }^{2}$ \\ 'Department of Neurology, Smt. B. K. \\ Shah Medical Institute and Research \\ Centre, Sumandeep Vidyapeeth \\ University, Vadodara, Gujarat, India; \\ ${ }^{2}$ Department of Neurology, Cleveland \\ Clinic Foundation, Cleveland, $\mathrm{OH}$, \\ USA
}

Abstract: Hemicrania continua (HC) is an indomethacin-responsive primary headache disorder which is currently classified under the heading of trigeminal autonomic cephalalgias (TACs). It is a highly misdiagnosed and underreported primary headache. The pooled mean delay of diagnosis of $\mathrm{HC}$ is $8.0 \pm 7.2$ years. It is not rare. We noted more than 1000 cases in the literature. It represents $1.7 \%$ of total headache patients attending headache or neurology clinic. Just like other TACs, it is characterized by strictly unilateral pain in the trigeminal distribution, cranial autonomic features in the same area and agitation during exacerbations/ attacks. It is different from other TACs in one aspect. While all other TACs are episodic, HC patients have continuous headaches with superimposed severe exacerbations. The central feature of HC is continuous background headache. However, the patients may be worried only for superimposed exacerbations. Focusing only on exacerbations and ignoring continuous background headache are the most important factors for the misdiagnosis of $\mathrm{HC}$. A large number of patients may have migrainous features during exacerbation phase. Up to $70 \%$ patients may fulfill the diagnostic criteria for migraine during exacerbations. Besides migraine, its exacerbations can mimic a large number of other primary and secondary headaches. The other specific feature of $\mathrm{HC}$ is a remarkable response to indomethacin. However, a large number of patients develop side effects because of the long-term use of indomethacin. A few other medications may also be effective in a subset of patients with HC. Various surgical interventions have been suggested for patients who are intolerant to indomethacin. Several aspects of $\mathrm{HC}$ are still not defined. There is a great heterogeneity in types of patients or articles on the $\mathrm{HC}$ in the literature. Diagnostic criteria have been modified several times over the years. The current diagnostic criteria are too restrictive in some aspects. We suggest a more accommodating type of criteria for the appendix of International Classification of Headache Disorder (ICHD).

Keywords: side-locked headache, indomethacin, indomethacin-responsive headache, trigeminal autonomic cephalalgias

\section{Introduction}

Hemicrania continua (HC) is an indomethacin-responsive primary headache disorder which is currently classified under the heading of trigeminal autonomic cephalalgias (TACs), along with cluster headache $(\mathrm{CH})$, paroxysmal hemicrania $(\mathrm{PH})$, short-lasting unilateral neuralgiform headache attacks with conjunctival injection and tearing (SUNCT) and short-lasting unilateral neuralgiform headache attacks with cranial autonomic symptoms (SUNA). ${ }^{1}$
Correspondence: Sanjay Prakash Department of Neurology, Smt. B. K. Shah Medical Institute and Research Centre, Piparia, Vadodara 3901760, Gujarat, India Email drprakashs@yahoo.co.in 


\section{History of HC}

Medina and Diamond ${ }^{2}$ were probably the first authors to describe the clinical phenotype of HC. They reported 54 patients under the heading of cluster headache variants. A total of 28 patients had background vascular headache, and 15 patients (out of 28) had a complete or excellent response to indomethacin. Therefore, it is believed that a subset of patients of that series actually had HC. The term "Hemicrania continua" was later coined by Sjaastad and Spierings. ${ }^{3}$

Although more than 35 years have passed since the first description of $\mathrm{HC}$, it is still an enigma in terms of clinical features, natural course, diagnostic criteria and therapeutic measures. The diagnostic criteria for $\mathrm{HC}$ have been repeatedly modified and revised over 2 decades. Even the nosological status of HC is debatable. The International Headache Society (IHS) Classification Committee (second edition, 2004) put it under the heading of "other primary headaches". ${ }^{4}$ However, International Classification of Headache Disorder, third edition (ICHD-3 $\beta, 2013$ ), has considered it as a family member of TACs. ${ }^{1}$

\section{Literature review}

Various aspects of $\mathrm{HC}$ have not yet been completely elucidated. Repeated modification of diagnostic criteria over the years is the evidence of it. There is a great heterogeneity in types of patients or articles on the $\mathrm{HC}$ in the literature. The first review of $\mathrm{HC}$ included only 18 patients. ${ }^{5}$ The last review was published a long back in 2001, which included a total of 93 patients. ${ }^{6}$ Several large case series have been published in the recent past. Therefore, we planned to review all cases reported in the literature.

We searched Medline/PubMed with "Hemicrania continua" as a keyword. All the case reports and case series of $\mathrm{HC}$ were reviewed. We carefully reviewed the reference lists of all the articles found on $\mathrm{HC}$ to look for additional cases. All articles that mentioned a case of $\mathrm{HC}$ were included for the review.

We noted 171 articles, in which at least one case of $\mathrm{HC}$ was described or mentioned. These articles include 1002 cases with a diagnosis of HC (Supplementary materials). More than 900 cases of $\mathrm{HC}$ are reported in the literature since the last review (2001). ${ }^{6}$ However, a possibility of case duplication in the articles is also there. We included all the cases where the authors had claimed a possibility of HC. A large number of cases of $\mathrm{HC}$ have been presented in various conferences. We included only two of them. ${ }^{7,8}$ Therefore, the total number of cases of $\mathrm{HC}$ in the literature may be even more than that. We did not verify it for the diagnostic accuracy according to the current ICHD-3 $\beta$ criteria.
In the past years, a large number of single case or small series on HC had been published. However, several large case series have been published in the recent past. There are at least 28 articles, each reporting $\geq 10$ patients with HC. However, these cases have been described in different clinical settings. For epidemiological and clinical feature analyses, we included only those studies that described a consecutive series of $\mathrm{HC}$ patients (at least five patients).

There are several case series that have focused mainly on the different therapeutic aspects of HC. A few cases of $\mathrm{HC}$ were just the part of some epidemiological studies (and lack epidemiological and clinical details). A few studies have focused on the pathophysiological aspects of HC. As these cases do not truly represent the consecutive patients with $\mathrm{HC}$, we excluded such cases for the epidemiological and clinical feature analyses. Secondary cases of $\mathrm{HC}$ were not included in this review and they were analyzed separately.

We noted 14 case series (a total of 472 patients) that described consecutive cases of HC. However, there was no uniformity in reporting $\mathrm{HC}$ cases in these publications, as they had followed only those diagnostic criteria that were prevalent at that time. Various epidemiological and clinical parameters were not available in some reports. Epidemiological and clinical data are summarized and pooled with descriptive statistics in different tables 1-9.

\section{Epidemiology}

The literature lacks data about the prevalence of $\mathrm{HC}$ in the general population. A response to indomethacin is an essential feature in the diagnostic criteria of HC. ${ }^{1}$ It makes it hard to find out the prevalence of (definite) $\mathrm{HC}$ in any general population. Sjaastad and Bakketeig ${ }^{9}$ noted 18 patients (1.0\%) with clinical features resembling $\mathrm{HC}$ in 1838 parishioners in the Vågå study.

Several clinic-based studies suggest that HC is not uncommon, but it is probably an underdiagnosed condition. Table 1 shows the prevalence of $\mathrm{HC}$ in the neurology or headache clinic. HC represents $1.7 \%$ (range $1.3 \%-2.3 \%$ ) of total headache patients attending headache or neurology clinic.

There are two clinic-based studies on the strictly unilateral headaches. Pooled analyses of these two studies indicate that $\mathrm{HC}$ is the second most common TACs in the clinical setting. Overall, $\mathrm{HC}$ is the fourth most common cause of side-locked headaches (after $\mathrm{CH}$, side-locked migraine and cervicogenic headache).$^{10}$

The diagnosis of $\mathrm{HC}$ may be missed even by neurologists and headache experts. Rossi et al ${ }^{11}$ discussed the diagnostic issue of $\mathrm{HC}$ in their 25 newly diagnosed cases of HC. A total 
Table I Percentage of $\mathrm{HC}$ patients among total headache patients in clinical settings

\begin{tabular}{lllc}
\hline Study & Number of HC & Total headache patients & Proportion of HC of total headache patients (\%) \\
\hline Prakash et al $^{67}$ & 22 & 1687 & 1.3 \\
Benítez-Rivero et al $^{26}$ & 12 & 520 & 2.3 \\
Ramón et al $^{68}$ & 8 & 528 & 1.5 \\
Cortijo et al $^{12}$ & 36 & 1800 & 2.0 \\
Guerrero et al $^{34}$ & 22 & 1150 & 1.9 \\
Rossi et al & 25 & 1612 & 1.6 \\
Total & 125 & 7297 & 1.7 \\
\hline
\end{tabular}

Abbreviation: $\mathrm{HC}$, hemicrania continua.

of 20 cases $(80 \%)$ were initially seen by neurologists without suspecting a diagnosis of $\mathrm{HC}$, and seven cases (28\%) were previously evaluated at headache centers without making a correct diagnosis. Therefore, with such a high rate of misdiagnosis, we can presume that the prevalence of $\mathrm{HC}$ should be much higher than the current data. With more inclusive type criteria in ICHD-3 $\beta$, the prevalence will definitely rise.

\section{Age}

The mean age at the onset of $\mathrm{HC}$ varies between 31 and 53 years in different case series. The pooled mean age at the onset was 40 years $(n=472)$. In Cortijo et al's ${ }^{12}$ series ( $n$ $=36)$, 25 patients $(69 \%)$ were $\geq 40$ years. However, no age group is immune and it can begin at any part of the life. The age range at the onset was 5-76 years (Table 2).

\section{Sex}

$\mathrm{HC}$ is classically considered a disease with a female preponderance. In an earlier review, the female to male ratio was 5:1. ${ }^{5}$ This female preponderance reduced to 2.8:1 in Peres et al's ${ }^{6}$ review. In the current pooled analysis of the 472 patients, the female to male ratio is 1.8:1 (Table 2).

\section{Familial HC}

There is only one case report of familial HC (two members of the family). ${ }^{13}$ However, no genetic susceptibility has been confirmed.

\section{Clinical features}

$\mathrm{HC}$ is characterized by a strictly unilateral, continuous headache of moderate intensity, with superimposed exacerbations of severe intensity. The exacerbations are associated with cranial autonomic features, restlessness and migrainous features. By definition, there should be a complete response to indomethacin.

\section{Laterality}

$\mathrm{HC}$ is a strictly unilateral head pain. There was a slight preference for the right side ( $53 \%$ vs $45 \% ; n=169)$. The preponderance for right side was also noted in an earlier review. ${ }^{5}$ Only

Table 2 Epidemiological parameters in $\mathrm{HC}$ as reported in a case series describing consecutive patients ( $>5$ patients) and pooled analyses

\begin{tabular}{|c|c|c|c|c|c|c|c|c|c|}
\hline \multirow[t]{2}{*}{ Study } & \multirow[t]{2}{*}{$\begin{array}{l}\text { Number of } \\
\text { patients }\end{array}$} & \multicolumn{2}{|c|}{ Sex (male/female) } & \multicolumn{2}{|c|}{$\begin{array}{l}\text { Age at the onset } \\
\text { (years) }\end{array}$} & \multicolumn{2}{|c|}{$\begin{array}{l}\text { Delay in diagnosis } \\
\text { (months) }\end{array}$} & \multicolumn{2}{|c|}{ Pattern of HC } \\
\hline & & Number & Ratio & Mean & Range & Mean & Range & Continuous & Remitting \\
\hline Benítez-Rivero et $\mathrm{al}^{26}$ & 12 & $4 / 8$ & $\mathrm{I}: 2$ & 47.1 & $26-75$ & 96 & - & - & - \\
\hline Guerrero et $\mathrm{al}^{34}$ & 22 & $8 / 14$ & $\mathrm{I}: \mathrm{I} .7$ & 41.8 & $7-74$ & - & - & 86 & 14 \\
\hline Cortijo et al $^{12}$ & 36 & $8 / 28$ & $\mathrm{I}: 3.5$ & 46.3 & $14-74$ & 75 & $3-390$ & 89 & II \\
\hline Prakash and Golwala ${ }^{29}$ & 62 & $29 / 33$ & I:I.I & 41.8 & $28-61$ & 50 & $3-264$ & 78 & 22 \\
\hline de Moura et $\mathrm{al}^{28}$ & 10 & $4 / 6$ & $\mathrm{I}: \mathrm{I} .5$ & 31 & $6-59$ & 204 & $21-456$ & - & - \\
\hline Cittadini and Goadsby ${ }^{14}$ & 39 & $15 / 24$ & $\mathrm{I}: \mathrm{I} .6$ & 38.7 & $10-67$ & - & - & 82 & 18 \\
\hline Rossi et al"I & 25 & $11 / 14$ & $\mathrm{I}: \mathrm{I} .3$ & 45.3 & $22-66$ & 60 & $6-204$ & - & - \\
\hline Marmura et al ${ }^{65}$ & 165 & $66 / 99$ & $\mathrm{I}: \mathrm{I} .5$ & - & - & - & - & - & - \\
\hline Bigal et $\mathrm{al}^{37}$ & 10 & $3 / 7$ & $\mathrm{I}: 2.3$ & 45.4 & $34-61$ & - & - & - & - \\
\hline Peres et $\mathrm{al}^{6}$ & 34 & $10 / 24$ & $\mathrm{I}: 2.4$ & 28 & $5-67$ & 252 & - & 88 & 12 \\
\hline Wheeler $^{7}$ & 30 & $1 / 29$ & $\mathrm{I}: 29$ & 42.3 & $13-76$ & 100 & - & - & - \\
\hline Espada et $\mathrm{al}^{8}$ & 9 & $5 / 4$ & $\mathrm{I}: 0.8$ & 53.3 & $29-69$ & 16 & $1-48$ & 89 & II \\
\hline Newman et $\mathrm{al}^{25}$ & 10 & $6 / 4$ & $\mathrm{I}: 0.6$ & 35 & $12-45$ & 47 & $\mathrm{I}-94$ & 90 & 10 \\
\hline Bordini et $\mathrm{al}^{5}$ & 8 & $\mathrm{I} / 7$ & $\mathrm{I}: 7$ & 38.4 & $22-58$ & 52 & $1-180$ & 88 & 12 \\
\hline Average & & $|7| / 30 \mid$ & $\mathrm{I}: \mathrm{I} .8$ & 39.7 & $5-76$ & 95 & $3-456$ & 85 & 15 \\
\hline
\end{tabular}

Note: '-' indicates data not available.

Abbreviation: $\mathrm{HC}$, hemicrania continua. 
one case series noted side-shifting HC. It composes $8 \%$ of total patients in that series. ${ }^{14}$ However, on pooled analysis, the prevalence of side-shifting $\mathrm{HC}$ was $\sim 2 \%$. There are at least nine cases with side-shifting pain in the literature. ${ }^{15-20} \mathrm{~A}$ few case reports of bilateral $\mathrm{HC}$ have also been reported in the literature. Pasquier et $\mathrm{al}^{21}$ reported the first case of the bilateral $\mathrm{HC}$ in a 38-year female. The patient had a 7-year history of fluctuating holocephalic headaches without cranial autonomic features. The headache did not respond to any drug. However, there was a complete response to indomethacin. After that, three more cases of bilateral $\mathrm{HC}$ have been reported. ${ }^{22-24}$

\section{Site of pain}

The pain of all TACs classically present in the ophthalmic division of the trigeminal nerve (V1).

ICHD-3 $\beta$ defines the sites of pain for $\mathrm{CH}, \mathrm{PH}$ and SUNCT/SUNA. The pain can be in orbital, supraorbital, temporal or in any combination of these sites. However, ICHD-3 $\beta$ is silent over the sites of pain in HC patients. It mentions just "unilateral pain." Table 3 shows the sites of pain in patients with $\mathrm{HC}$ in different case series. It suggests that just like other TACs, $\mathrm{HC}$ patients have pain predominantly in V1 distributions. Therefore, we suggested to include the sites of pain (orbital, supraorbital or temporal) in the diagnostic criteria of $\mathrm{HC}$, as defined in the diagnostic criteria for $\mathrm{CH}$, PH and SUNCT/SUNA.

A continuous background pain is usually localized in V1 distribution. However, the pain may spread during exacerbation phase to involve other areas such as occiput, neck, shoulder, maxilla, periauricular region and oral cavity (including teeth and throat). ${ }^{14}$

\section{Pain characteristics and pattern}

The pain has two components: 1) continuous unilateral headache and 2) superimposed variable exacerbations. The recognition of both components is important for identifying a case of HC. Figure 1 shows the diagrammatic representation of pain pattern in $\mathrm{HC}$.

Continuous baseline headache is the most consistent feature of HC. It is the central feature of $\mathrm{HC}$.

The majority of patients have superimposed exacerbations over the basal pain. Superimposed exacerbations are highly variable in terms of character, intensity, duration, frequency and associated features during exacerbations. Table 4 summarizes the various aspects of the exacerbation phase. This variability may be the reason for the high rate of misdiagnosis of HC. Therefore, an understanding of exacerbation phase is very important to reduce the misdiagnosis of $\mathrm{HC}$.

Table 3 Sites of pain in patients with HC in different clinical studies

\begin{tabular}{|c|c|c|c|c|c|}
\hline Sites of pain & $\begin{array}{l}\text { Benítez-Rivero } \\
\text { et } \mathrm{al}^{26}(\%)\end{array}$ & Cortijo et al ${ }^{12}$ (\%) & $\begin{array}{l}\text { Prakash and } \\
\text { Golwala }^{29}(\%)\end{array}$ & $\begin{array}{l}\text { Cittadini and } \\
\text { Goadsby }^{14}(\%)\end{array}$ & Newman et $\mathrm{al}^{25}(\%)$ \\
\hline Orbital/retro-orbital & 50 & 62 & 83 & $67 / 59^{*}$ & 70 \\
\hline Frontal & 33 & 8 & 57 & 64 & 20 \\
\hline Temporal & - & 8 & 70 & 82 & 50 \\
\hline Parieto-occipital & 25 & 8 & 37 & 54 & 40 \\
\hline Periauricular/ear & - & - & 13 & 30 & - \\
\hline Infra-orbital/maxillary & - & - & 47 & 30 & 10 \\
\hline Teeth & - & - & 20 & 20 & - \\
\hline Neck & - & - & 7 & 33 & 10 \\
\hline Shoulder & - & - & - & 18 & 10 \\
\hline Hemicranial & 25 & 31 & - & - & 40 \\
\hline
\end{tabular}

Notes: *Orbital and retro-orbital are described separately. '-' indicates data not available. Abbreviation: $\mathrm{HC}$, hemicrania continua.

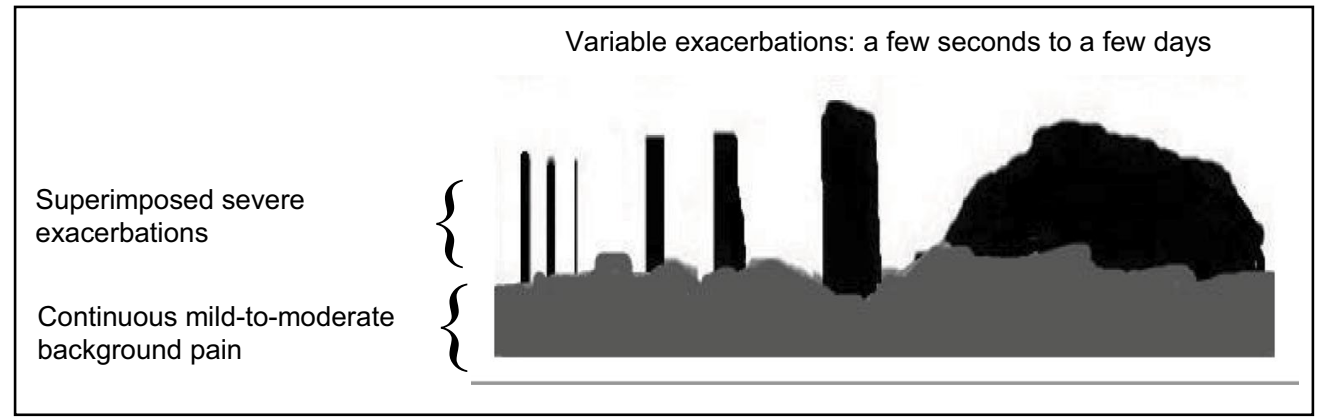

Figure I Diagrammatic representation of hemicrania continua. 
Table 4 Clinical characteristics of superimposed exacerbations in $\mathrm{HC}$ as reported in case series describing consecutive patients $(>5$ patients) and pooled analyses

\begin{tabular}{|c|c|c|c|c|c|c|c|c|}
\hline \multirow[t]{2}{*}{ Study } & \multirow{2}{*}{$\begin{array}{l}\text { Intensity } \\
\text { (VAS), M; R }\end{array}$} & \multirow{2}{*}{$\begin{array}{l}\text { Character } \\
\text { of pain }\end{array}$} & \multirow{2}{*}{$\begin{array}{l}\text { Duration } \\
\text { (M and/or } R \text { ) }\end{array}$} & \multirow{2}{*}{$\begin{array}{l}\text { Frequency } \\
\text { (M and/or } R)\end{array}$} & \multirow{2}{*}{$\begin{array}{l}\text { Autonomic } \\
\text { features, at } \\
\text { least one (\%) }\end{array}$} & \multicolumn{2}{|c|}{ Migrainous features } & \multirow{2}{*}{$\begin{array}{l}\text { Agitation } \\
\text { (\%) }\end{array}$} \\
\hline & & & & & & $\begin{array}{l}\text { At least } \\
\text { one (\%) }\end{array}$ & $\begin{array}{l}\text { Fulfilling } \\
\text { migraine } \\
\text { criteria (\%) }\end{array}$ & \\
\hline $\begin{array}{l}\text { Benítez-Rivero } \\
\text { et } \mathrm{al}^{26}\end{array}$ & 9.2 & - & $\begin{array}{l}\text { M } 31.4 \text { hours } \\
\text { R I-72 hours }\end{array}$ & $\begin{array}{l}\text { Daily - one attack } \\
\text { in } 2 \text { months }\end{array}$ & 81 & - & - & - \\
\hline Cortijo et al ${ }^{12}$ & $8.3 ; 5-10$ & $\begin{array}{l}\text { Stabbing } 52 \% \\
\text { Pulsatile } 6 \%\end{array}$ & $\begin{array}{l}\text { M } 32.3 \text { minutes } \\
\text { R I-60 minutes }\end{array}$ & $\begin{array}{l}\text { Multiple daily } \\
\text { attacks }\end{array}$ & 69 & 17 & - & - \\
\hline $\begin{array}{l}\text { Prakash and } \\
\text { Golwala }^{29}\end{array}$ & & $\begin{array}{l}\text { Pulsatile } 62 \% \\
\text { Non-pulsatile } 72 \%\end{array}$ & $\begin{array}{l}\mathrm{R}<5 \text { minute to } \\
>24 \text { hours }\end{array}$ & $\begin{array}{l}<\text { I/day to }>5 \\
\text { attack/day }\end{array}$ & 79 & 61 & - & 56 \\
\hline de Moura et $\mathrm{al}^{28}$ & $9-10$ & Pulsatile $50 \%$ & - & - & 100 & - & - & - \\
\hline $\begin{array}{l}\text { Cittadini and } \\
\text { Goadsby }{ }^{14}\end{array}$ & $9.3 ; 6.5-10$ & $\begin{array}{l}\text { Pulsatile } 69 \% \\
\text { Lancinating } 43 \%\end{array}$ & $\begin{array}{l}\mathrm{R} 30 \text { minutes to } \\
7 \text { days }\end{array}$ & $\begin{array}{l}\text { Daily - one attack } \\
\text { in } 4 \text { months }\end{array}$ & 95 & 79 & $>53$ & 69 \\
\hline Rossi et al"I & $\begin{array}{l}\text { Moderate to } \\
\text { severe }\end{array}$ & Pulsatile $24 \%$ & $\begin{array}{l}\mathrm{R}<\mathrm{I} 5 \text { minutes to } \\
72 \text { hours }\end{array}$ & $<$ I/day to $>8 /$ day & 100 & 56 & 32 & 32 \\
\hline Marmura et $a^{65}$ & - & & - & - & 59 & 58 & 58 & - \\
\hline Bigal et $\mathrm{al}^{37}$ & - & Pulsatile $30 \%$ & - & - & 70 & 40 & - & - \\
\hline Peres et $\mathrm{al}^{6}$ & $9.3 \pm 1.0$ & $\begin{array}{l}\text { Pulsatile } 53 \% \\
\text { Stabbing } 41 \%\end{array}$ & - & - & 74 & 71 & 71 & - \\
\hline Wheeler ${ }^{7}$ & Severe & $\begin{array}{l}\text { Pulsatile } 53 \% \\
\text { Stabbing } 20 \%\end{array}$ & $\begin{array}{l}\text { M } 24 \text { hours } \\
\text { R I second to } \\
2 \text { weeks }\end{array}$ & $\begin{array}{l}\text { I0/day to I-3 } \\
\text { attacks/month }\end{array}$ & 97 & 90 & - & - \\
\hline Newman et $\mathrm{al}^{25}$ & $\begin{array}{l}\text { Severe to } \\
\text { excruciating }\end{array}$ & $\begin{array}{l}\text { Pulsatile } 30 \% \\
\text { Stabbing } 40 \%\end{array}$ & $\begin{array}{l}\text { R } 30 \text { seconds to } \\
\text { I } 2 \text { hours }\end{array}$ & $\begin{array}{l}\text { I0-20/daily to } \\
2-3 / \text { week }\end{array}$ & 60 & 40 & - & 10 \\
\hline Bordini et $\mathrm{al}^{5}$ & Severe & $\begin{array}{l}\text { Pulsatile } 39 \% \\
\text { Stabbing } 100 \%\end{array}$ & $\begin{array}{l}\text { R } 5 \text { hours to } \\
8 \text { days }\end{array}$ & - & Present & Present & - & - \\
\hline Average & $9.0 ; 5-10$ & & A few seconds to & 20 attacks/day to & 74 & 60 & 56 & 52 \\
\hline Range & & & 2 weeks & one in 4 months & $59-100$ & $17-90$ & $32-71$ & $10-69$ \\
\hline
\end{tabular}

Notes: '-' indicates data not available.

Abbreviations: $\mathrm{HC}$, hemicrania continua; $M$, mean; R, range; VAS, visual analog scale.

\section{Character and intensity of pain}

The background pain is usually perceived as dull and pressure (like tension-type headache [TTH]; Peres et al 73\%; Wheeler et al $67 \%$ ). However, a few patients may have throbbing or stabbing background pain. It is usually mild to moderate in intensity. The mean visual analog scale (VAS 0-10) of the continuous background pain varies from 3.3 to 5.2. However, a few patients may have a persistent severe headache ( $>7$ in VAS). In a series of 39 patients reported by Cittadini and Goadsby, ${ }^{14}$ two patients had continuous pain with a severity score of 10 . The background pain usually does not hamper physical activity. In a case series of 34 patients reported by Peres et al, ${ }^{6} 82 \%$ patients had either no or very mild physical disability because of the baseline pain.

The character of pain during exacerbation phase are largely either throbbing or stabbing (jabs and jolts). Therefore, whereas the characteristics of basal pain are predominantly like TTH, the exacerbations are predominantly like migraine.

The intensity of exacerbations is usually severe to very severe (VAS score $>7$ ). The pooled mean VAS of exacerba- tions pain was $9.0(\mathrm{n}=121)$. However, it ranges from 5 to 10 . Approximately $38 \%$ patients rated the severe pain at 10. In Cittadini and Goadsby's series, ${ }^{14} 49 \%$ patients said that their pains were the most painful conditions they had ever experienced, comparing it to childbirth, a broken bone, toothache and burned hands. In this regard, it matches with the patients with $\mathrm{CH}$ and $\mathrm{PH}$. Like $\mathrm{CH}$ and $\mathrm{PH}$, the patients with $\mathrm{HC}$ may have suicidal thoughts during severe exacerbations. There are a few cases of HC where patients attempted suicide because of the intolerable pain. ${ }^{5}$

$\mathrm{CH}$ is considered as a most painful condition. The pain intensity of $\mathrm{PH}$ is almost similar to $\mathrm{CH}$. The data on $\mathrm{HC}$ suggest that the intensity of the exacerbation attacks of $\mathrm{HC}$ may be as severe as of $\mathrm{CH}$ and $\mathrm{PH}$ in a large number of patients. However, on the other hand, up to $18 \%$ patients may have VAS score $<7$ (i.e., only moderate exacerbations). ${ }^{11,12,14}$ Moreover, a few patients may not experience exacerbation phase and will have only continuous background pain without much fluctuation. ${ }^{14,25}$ 


\section{Duration and frequency of exacerbations} $\mathrm{CH}, \mathrm{PH}$ and SUNCT/SUNA follow a predictable pattern in relation to frequency and duration of attacks. ${ }^{1}$ However, the pattern of exacerbations of $\mathrm{HC}$ does not follow any rule (Table 4). It is highly variable. This may vary from attack per attack. The mean duration of exacerbations in one series was 32 minutes. ${ }^{12} \mathrm{How}-$ ever, in another series, it was 31 hours. ${ }^{26}$ The range of duration of exacerbations varies from a few seconds to 2 weeks. ${ }^{7}$ The frequency of the attacks is also variable. It varies from more than 20 attacks in a day to one attack in 4-month duration (Table 4). Pooling of the data of frequency and durations was meaningless here. The key point is to know that the duration and frequency of exacerbations do not have any boundary.

Nocturnal exacerbations are quite common in $\mathrm{HC}$ (up to $53 \%) .{ }^{14}$ However, a circadian periodicity for exacerbations remains absent. However, a few patients noted worsening of exacerbations in particular months. ${ }^{14,27}$ Cittadini and Goadsby reported three patients, where the worsening of the pains was noted in particular months.

\section{Ipsilateral cranial autonomic symptoms (CAS)}

These are very important accompanying features of all five types of TACs, including HC. ICHD- $3 \beta$ recognizes 10 different types of cranial autonomic features. These CAS are related to eye/eyelid (conjunctival injection, lacrimation, ptosis, meiosis and eyelid edema), nose (rhinorrhea and nasal congestion), ear (sensation of fullness) and face (flushing and sweating). ${ }^{1}$

The mean prevalence of at least one cranial autonomic feature was $74 \%$ in pooled analyses $(n=433)$. In an earlier review, the prevalence of at least one cranial autonomic feature was $63 \%{ }^{25}$ This prevalence is slightly lower than the prevalence of $\mathrm{CAS}$ in $\mathrm{CH}$ and $\mathrm{PH}$ patients, where it is noted in more than $90 \%$ cases. However, a few case series of $\mathrm{HC}$ have also reported CAS in more than $90 \%$ cases. ${ }^{7111,14,28}$ Variability in the prevalence of CAS may be because of the selection bias in the particular series, as the importance of CAS for the diagnostic purpose has repeatedly been changed over the time.

Moreover, CAS may be subtle in a subset of patients and patients may not be aware of its presence. In a series of 62 patients reported by Prakash et al, ${ }^{29}$ nine patients initially denied the presence of any CAS. However, CAS were noted later, on an objective assessment of the patients for CAS. Therefore, an objective assessment of autonomic feature is important before labeling it as "absent".

Tearing was the most common cranial autonomic feature (36\%-77\%) in all reported case series. . $^{711,14,25,28,29}$ Conjunctival injection, ptosis, nasal congestion and rhinorrhea are other common CAS in patients with HC. A sense of aural fullness has been recently included as one of the autonomic features of all TACs in ICHD-3 $\beta$. It has been reported only in Cittadini and Goadsby's ${ }^{14}$ case series, and they found it in $19 \%$ cases with HC.

Another important and a peculiar feature of $\mathrm{HC}$ is a feeling of foreign body sensation in the eye (or sand in eye sensation or itching eye). It is considered as part of CAS. It is noted in several large case series of HC (Prakash et al 43\%; Cittadini and Goadsby 32\%; Cortijo et al 32\%; Bordini et al 17\%). The feeling of foreign body sensation in the eye has not been reported in any other TACs or any primary headache disorder. It is not included in ICHD-3 $\beta$ criteria. We would suggest to include it in the diagnostic criteria of $\mathrm{HC}$ as a part of CAS.

\section{Restlessness or agitation}

A sense of restlessness or agitation is an important feature of TACs. It has been the part of the diagnostic criteria of $\mathrm{CH}$ since long. Very recently, restlessness has also been included in HC criteria. ${ }^{1}$ It is included as an alternative to cranial autonomic features. The mean prevalence of agitation or restlessness was $52 \%$ in pooled analyses $(n=136$; range $10 \%-69 \%)$.

\section{Migrainous features}

Nausea, vomiting, photophobia and phonophobia are called as migrainous features. It is quite common in patients with $\mathrm{HC}$. The prevalence of at least one migrainous feature varies from $17 \%$ to $90 \%$ (with mean pooled prevalence of $60 \%$ ). A few studies compared the migraine criteria to the exacerbation phase of HC. Approximately 32\%-71\% (mean 56\%) patients meet the criteria for migraine in the exacerbation period. Visual auras have been reported during exacerbations in a few patients with HC. ${ }^{30,31}$ Olfactory aura has also been reported in one case of $\mathrm{HC} .{ }^{32}$

\section{Triggers of exacerbations}

Stress was the most common trigger in Cittadini and Goadsby's ${ }^{14}$ series. Approximately $51 \%$ patients noted exacerbations after stress or relaxation after stress. Exacerbations with alcohol and irregular sleep were noted in $38 \% .{ }^{14}$ Menstruation was a trigger in some patients. ${ }^{14}$ Prakash et al ${ }^{33}$ reported a case of relapsing-remitting $\mathrm{HC}$ that used to occur only during menstruation.

\section{Classification and variants of $\mathrm{HC}$}

$\mathrm{HC}$, by definition, is a chronic headache disorder. A minimum of 3-month duration is required before labeling a case as $\mathrm{HC}$. 
ICHD-3 $\beta$ recognizes two forms of $\mathrm{HC}$, based on whether the patient gets any symptom-free day or not: 1) HC, unremitting subtype and 2) HC, remitting subtype (Table 5). ${ }^{1}$

Unremitting $\mathrm{HC}$ is characterized by continuous pain for at least 1 year, without any symptom-free period. Interruption of pain for even 1 day is not required. In remitting $\mathrm{HC}$, the patient remains symptom free for at least 1 day. Unremitting $\mathrm{HC}$ (i.e., continuous pain for 1 year) can arise de novo or may evolve from remitting subtype. Table 2 lists the diagnostic distribution of both forms of $\mathrm{HC}$ in the literature. The prevalence of remitting $\mathrm{HC}$ varies between $10 \%$ and $22 \%$ of total $\mathrm{HC}$ cases (mean pooled prevalence $15 \% ; \mathrm{n}=220$ ).

Unremitting $\mathrm{HC}$ arising de novo (i.e., chronic from the onset) is more common than evolving from remitting subtype. Approximately $50 \%-60 \% \mathrm{HC}$ is chronic from the onset and $25 \%-35 \% \mathrm{HC}$ evolves into continuous phase from the remitting form. ${ }^{12,14,25,26,29,34}$

\section{Secondary HC}

Table 6 lists all the cases of $\mathrm{HC}$ that were claimed to be secondary HC. However, the diagnostic accuracy of HC and the causal association of headaches to the claimed pathologies are

Table 5 Diagnostic criteria of different subtypes of HC (ICHD-3 $\beta$ )

$3.4 \quad \mathrm{HC}$

A Unilateral headache fulfilling criteria $B-D$

B Present for $>3$ months, with exacerbations of moderate or greater intensity

C Either or both of the following:

I At least one of the following symptoms or signs, ipsilateral to the headache:

a) Conjunctival injection and/or lacrimation

b) Nasal congestion and/or rhinorrhea

c) Eyelid edema

d) Forehead and facial sweating

e) Forehead and facial flushing

f) Sensation of fullness in the ear

g) Miosis and/or ptosis

2 A sense of restlessness or agitation, or aggravation of the pain by movement

D Responds absolutely to therapeutic doses of indomethacin

E Not better accounted for by another ICHD-3 $\beta$ diagnosis

3.4.I HC, remitting subtype

A Headache fulfilling criteria for $3.4 \mathrm{HC}$ and criterion $\mathrm{B}$ below

$B$ Headache is not daily or continuous, but interrupted by remission periods of $\geq \mathrm{I}$ day without treatment

3.4.2 HC, unremitting subtype

A Headache fulfilling criteria for $3.4 \mathrm{HC}$ and criterion $\mathrm{B}$ below

B Headache is daily and continuous, for at least I year without remission periods of $\geq$ I day

Note: Data from The International Classification of Headache Disorders, 3rd (beta version).'

Abbreviations: $\mathrm{HC}$, hemicrania continua; ICHD-3 $\beta$, International Classification of Headache Disorder, third edition. not obvious in each case. All secondary HCs were classified and arranged according to ICHD- $3 \beta$ criteria. We noted a total of 66 cases of secondary HC. It included a total of 25 different pathologies. Posttraumatic $\mathrm{HC}$ was the most common entity. It composed $39 \%$ of total cases of secondary HC. Finkel et $\mathrm{al}^{35}$ studied the headache pattern in military service members with a history of mild traumatic brain injury. They noted 12 patients with $\mathrm{HC}$ (consisting $7.2 \%$ of total cases). This review is very important for two reasons. 1) It highlights that posttraumatic HC may be very common in the general population. 2) It will respond strikingly to indomethacin. Therefore, there is a need to make physicians aware of this entity. Second most common secondary $\mathrm{HC}$ is post-craniotomy $\mathrm{HC}$. It is almost equal to posttraumatic HC. Postpartum and postoperative $\mathrm{HCs}$ are two other secondary $\mathrm{HCs}$ that are in temporal relation to certain events. Therefore, any side-locked headache should be inquired about the presence of certain events preceding to $\mathrm{HC}$ (such as head injury, any type of surgery and postpartum). Event-related secondary $\mathrm{HC}$ is largely benign. ${ }^{36}$

However, other secondary $\mathrm{HC}$ is not that benign and a few of them may be life threatening and may require early diagnosis and urgent therapy. Intracranial space-occupying lesion (especially pituitary tumor, CP angle tumor, etc), vessels-related pathology (especially internal carotid artery [ICA] dissection, cortical venous thrombosis, etc) and pathologies related to extracranial surrounding tissues (sinusitis, nasopharyngeal carcinoma, eye pathology, etc) are very important causes of secondary HC. Prolactinoma is the most common intracranial structural pathology $(n=4)$. ICA dissection $(n=3)$ is the most common vascular pathology. Carcinoma lung is probably the most dangerous pathology associated with secondary HC.

\section{Other associated headache disorders}

HC has been observed in association with various other primary headaches and facial pain, including different neuralgias. Jabs and jolts like pain (stabbing headache) are important associated pains during exacerbation phase. They were noted in $20 \%-41 \%$ patients with $\mathrm{HC}$ in different case series. ${ }^{6,14,37}$ However, this prevalence matches with the normal prevalence of stabbing headache in the general population. Table 7 presents all other associated headaches reported in the literature. It can be classified into three groups: 1) "both $\mathrm{HC}$ and other primary headache disorder existing simultaneously": one headache may precede to other or both headaches may start simultaneously. However, patients may not be able to differentiate that they are having two diseases simultane- 
Table 6 Secondary HC (classified and arranged according to ICHD-3 $\beta$ criteria)

\begin{tabular}{|c|c|c|c|}
\hline ICHD-3 $\beta$ code & Diagnosis & & Number of patients \\
\hline \multirow[t]{3}{*}{5} & Headache attributed to trauma or injury to head and/or neck & & \\
\hline & & Posttraumatic $\mathrm{HC}^{\mid 4,29,35,36,42,69-71}$ & 26 \\
\hline & & Post-craniotomy $\mathrm{HC}^{29,42,72}$ & 6 \\
\hline \multirow[t]{7}{*}{6} & Headache attributed to cranial or cervical vascular disorder & & \\
\hline & & Poststroke $\mathrm{HC}^{42}$ & I \\
\hline & & Internal carotid artery aneurysm ${ }^{42}$ & I \\
\hline & & Venous malformation ${ }^{42}$ & I \\
\hline & & Internal carotid artery dissection ${ }^{42,73}$ & 3 \\
\hline & & Cerebral venous thrombosis ${ }^{74}$ & I \\
\hline & & Angiolipoma in temporal region ${ }^{42}$ & I \\
\hline \multirow[t]{5}{*}{7} & Headache attributed to nonvascular intracranial disorder & & \\
\hline & & Prolactinoma ${ }^{42,75}$ & 4 \\
\hline & & Pituitary infarct ${ }^{14}$ & I \\
\hline & & $\mathrm{CP}$ angle epidermoid $\mathrm{d}^{42}$ & I \\
\hline & & Pineal cyst ${ }^{42}$ & I \\
\hline \multirow[t]{3}{*}{8} & Headache attributed to a substance or its withdrawal & & \\
\hline & & Transdermal nitroglycerine ${ }^{76}$ & 1 \\
\hline & & Analgesic rebound ${ }^{42}$ & I \\
\hline \multirow[t]{2}{*}{9} & Headache attributed to infection & & \\
\hline & & $\mathrm{HIV}^{42}$ & I \\
\hline \multirow[t]{7}{*}{11} & Headache or facial pain attributed to disorder of the cranium a & nd structures around it & \\
\hline & & Sphenoidal tumor ${ }^{42}$ & 1 \\
\hline & & Sphenoid sinusitis ${ }^{42}$ & I \\
\hline & & Nasopharyngeal carcinoma ${ }^{29,77}$ & 2 \\
\hline & & Orbital tumor/pseudotumor ${ }^{78}$ & I \\
\hline & & Disk herniation ${ }^{42}$ & I \\
\hline & & Vitreous hemorrhage $^{14}$ & I \\
\hline \multirow[t]{2}{*}{13} & Painful cranial neuropathies and other facial pains & & \\
\hline & & Leprosy ${ }^{79,80}$ & 2 \\
\hline \multirow[t]{5}{*}{14} & Other headache disorders & & \\
\hline & & Postpartum ${ }^{42}$ & 2 \\
\hline & & Postoperative (non-intracranial) ${ }^{36}$ & 2 \\
\hline & & Carcinoma lung ${ }^{81-83}$ & 3 \\
\hline & Total secondary $\mathrm{HC}$ & & 66 \\
\hline
\end{tabular}

Note: Data from The International Classification of Headache Disorders, 3rd (beta version).'

Abbreviations: HC, hemicrania continua; ICHD-3 $\beta$, International Classification of Headache Disorder, third edition.

ously. The diagnosis of both diseases at the same time is very important as patients may require two different classes of drugs. $\mathrm{CH}$ is the most common associated headache in this group. Other reported headaches are migraine, TTH, trochlear headache, sexual headache and trigeminal neuralgia. 2) "HC evolving from other primary headaches": again $\mathrm{CH}$ is the most common entity. PH, SUNCT, migraine and Raeder syndrome are other diseases in this group. Cosentino et $\mathrm{al}^{38}$ described a patient with $\mathrm{CH}$ who first evolved into SUNCT, and later on SUNCT changed into HC. The diagnosis of this group is important for therapeutic purpose as treatment will change if patients evolve into HC. 3) "HC evolving into other primary headaches": Muller et a ${ }^{39}$ described an $\mathrm{HC}$ patient who developed $\mathrm{PH}$ on withdrawal of the effective drug. Rozen et $\mathrm{al}^{40}$ reported a patient with post-PH. The patient first developed HC and later on HC turned into LASH (longlasting autonomic symptoms with associated hemicrania).

\section{Diagnosis}

\section{Diagnostic delay}

The pooled mean delay of diagnosis of HC $(n=231)$ was $95 \pm 75$ months ( $8 \pm 7.2$ years). The range of the mean delay of diagnosis was 16-252 months (1.3-21 years). Various reasons can be speculated for this high rate of misdiagnosis.

Although $\mathrm{HC}$ is not rare, there is a perception that it is still rare. Various authors still mention Peres et al' $\mathrm{s}^{6}$ old review and suggest that there are just 100 cases in the literature. Physicians usually do not prefer to make a diagnosis of a rare headache disorder. Currently, we noted more than 1000 cases of $\mathrm{HC}$ in the literature. Unawareness about HC may be another important issue for the high rate of misdiagnosis of HC. However, a case of $\mathrm{HC}$ is missed even by neurologists and headache experts. It may be because of the wrong history or misinterpretation of the clinical features of $\mathrm{HC}$ 
Table 7 Occurrence of different headaches in patients with HC

\begin{tabular}{|c|c|c|c|}
\hline Case (reference) & Associated headache & Side concordance & Interrelation between two headaches \\
\hline \multicolumn{4}{|c|}{$\mathrm{HC}$ concurrent with other primary headache disorders } \\
\hline Totzeck et al ${ }^{84}$ & $\mathrm{CH}$ & Same side & Both $\mathrm{CH}$ and $\mathrm{HC}$ were started simultaneously \\
\hline Lisotto et $\mathrm{al}^{85}$ & $\mathrm{CH}$ & Contralateral & $\begin{array}{l}\text { A patient with } \mathrm{HC} \text { simultaneously developed (after } 4 \text { years) } \\
\text { contralateral } \mathrm{CH}\end{array}$ \\
\hline Saito et $\mathrm{al}^{86}$ & $\mathrm{CH}$ & Same side & $\mathrm{HC}$ evolved during cluster period of $\mathrm{CH}$ \\
\hline Robbins et $\mathrm{al}^{87}$ & $\mathrm{CH}$ and migraine & Same side & $\mathrm{HC}$ and $\mathrm{CH}$ evolved simultaneously in a migraineur \\
\hline Evers et $\mathrm{a}^{88}$ & FHM & Same side & $\mathrm{HC}$ evolved over FHM (after several years of migraine onset) \\
\hline Allena et $\mathrm{al}^{89}$ & CTTH & Same side & $\begin{array}{l}\text { The authors believed that a patient had both } \mathrm{HC} \text { and CTTH } \\
\text { simultaneously }\end{array}$ \\
\hline Cuadrado et a $\mathrm{a}^{90}$ & Primary trochlear headache & Same side & An $\mathrm{HC}$ patient had probable trochlear headache simultaneously \\
\hline Prakash and Rathore ${ }^{91}$ & $\mathrm{TN}$ (two cases) & $\begin{array}{l}\text { Same side } \\
\text { same side }\end{array}$ & $\begin{array}{l}\text { Case I: } \mathrm{HC} \text { developed after several years of TN } \\
\text { Case 2: Both } \mathrm{HC} \text { and TN probably developed simultaneously }\end{array}$ \\
\hline Prakash $^{92}$ & Sexual headache & Same side & $\begin{array}{l}\text { Headache with sexual activity developed over the undiagnosed } \\
\text { case of } \mathrm{HC}\end{array}$ \\
\hline \multicolumn{4}{|c|}{$\mathrm{HC}$ evolving from other primary headaches } \\
\hline Porzukowiak ${ }^{93}$ & $\begin{array}{l}\text { Raeder paratrigeminal } \\
\text { neuralgia }\end{array}$ & Same side & $\begin{array}{l}\text { Initial symptoms of HC closely mimicked Raeder paratrigeminal } \\
\text { neuralgia }\end{array}$ \\
\hline Koutsis et $\mathrm{al}^{94}$ & Benign Raeder syndrome & Same side & Benign Raeder syndrome turned into $\mathrm{HC}$ over 10 months \\
\hline $\begin{array}{l}\text { Castellanos-Pinedo } \\
\text { et al }{ }^{95}\end{array}$ & $\mathrm{PH}$ & Same side & $\begin{array}{l}\text { A patient with episodic } \mathrm{PH} \text { developed } \mathrm{HC} \text { after a long remission } \\
\text { from } \mathrm{PH}\end{array}$ \\
\hline Terlizzi et al ${ }^{96}$ & Migraine & Same side & $\mathrm{HC}$ evolved after 10 years of episodic migraine \\
\hline Palmieri et $\mathrm{al}^{97}$ & Migraine & Same side & $\begin{array}{l}\text { A side-locked migraine (with aura) turned into } \mathrm{HC} \text { after } 25 \\
\text { years }\end{array}$ \\
\hline Cosentino et a $\left.\right|^{38}$ & CH-SUNCT & Same side & $\mathrm{A} C \mathrm{CH}$ patient first changed pattern as SUNCT, and later on $\mathrm{HC}$ \\
\hline Lambru et al ${ }^{98}$ & $\mathrm{CH}$ & Same side & A refractory $\mathrm{CH}$ suddenly evolved into $\mathrm{HC}$ \\
\hline Centonze et a $\left.\right|^{99}$ & $\mathrm{CH}$ & Same side & $\mathrm{HC}$ evolved after 10-month remission of $\mathrm{CH}$ \\
\hline Rozen ${ }^{100}$ & $\mathrm{CH}$ & Contralateral & $\mathrm{HC}$ evolved in remission phase of $\mathrm{CH}$ \\
\hline Rozen $^{40}$ & $\mathrm{PH}$ & Same side & $\begin{array}{l}\text { Posttraumatic PH that turned into HC. Later, it turned into } \\
\text { LASH syndrome }\end{array}$ \\
\hline \multicolumn{4}{|c|}{$\mathrm{HC}$ evolving into other primary headaches } \\
\hline Müller and Bekkelund ${ }^{39}$ & $\mathrm{PH}$ & Same side & A HC patient developed $\mathrm{PH}$ on withdrawal of the effective drug \\
\hline Rozen $^{40}$ & LASH & Same side & $\begin{array}{l}\text { Posttraumatic PH that turned into HC. Later, it turned into } \\
\text { LASH syndrome }\end{array}$ \\
\hline
\end{tabular}

Abbreviations: $\mathrm{CH}$, cluster headache; CTTH, chronic tension-type headache; FHM, familial hemiplegic migraine; HC, hemicrania continua; LASH, long-lasting autonomic symptoms with associated hemicrania; $\mathrm{PH}$, paroxysmal hemicrania; SUNCT, short-lasting unilateral neuralgiform headache attacks with conjunctival injection and tearing; $\mathrm{TN}$, trigeminal neuralgia.

patients. The patients may be worried of their superimposed exacerbations and may not volunteer about background headache. Even physician may not ask about background headaches. Patients may also not be aware of subtle cranial autonomic features. Objective assessment during attacks may be required. Phenotypic variability of HC may lead a physician to make a wrong diagnosis. Frequency and duration of headaches are important clues for diagnosing various primary headaches, secondary headaches and neuralgias. The duration and frequency of superimposed exacerbations mimic almost all primary headaches and neuralgias.

\section{Effects of diagnostic delay}

Patients who unnecessarily suffer from severe pain are very much treatable. Delay in diagnosis leads to unnecessary therapeutic intervention, including surgical procedures.
Approximately $36 \%$ patients with $\mathrm{HC}$ had undergone ineffective and unnecessary surgery in Rossi et al's ${ }^{11}$ series. Dental extraction and sinus surgery are two common unnecessary surgical interventions in $\mathrm{HC}$.

\section{Differential diagnosis}

There are two components of HC: 1) strictly unilateral continuous background headache and 2) superimposed exacerbations (Figure 1). Differential diagnosis depends on which components you are focusing (Figure 2).

The diagnosis could be very easy if one can recognize both components in a patient. Here, one will have to differentiate $\mathrm{HC}$ with $\mathrm{CH}$ or $\mathrm{PH}$ with interparoxysmal pain. However, $\mathrm{HC}$ can be easily differentiated with $\mathrm{CH} / \mathrm{PH}$ with interparoxysmal pain on the following grounds: 1) Interparoxysmal pain is not present throughout the day and it is usually very 


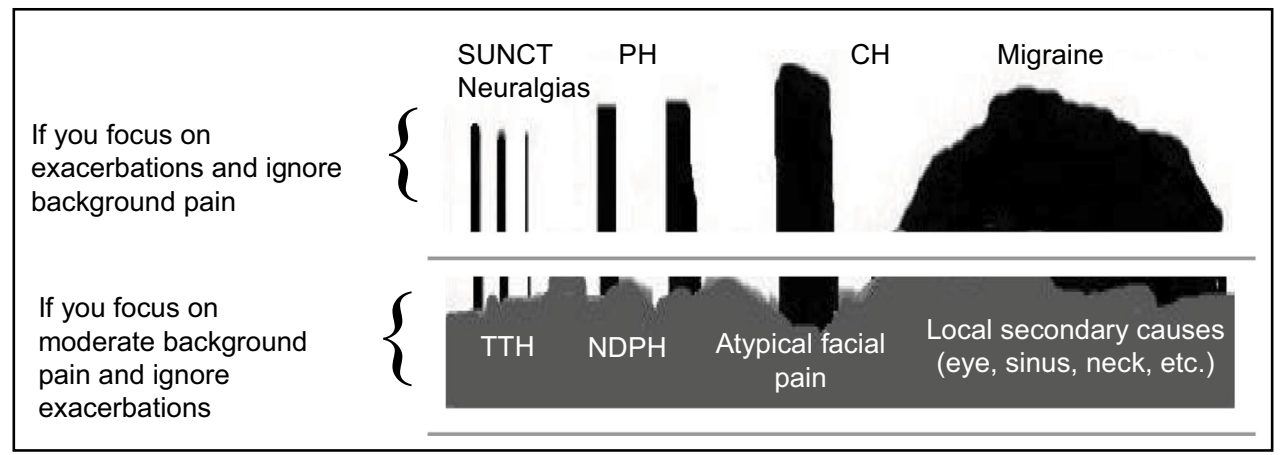

Figure 2 Differential diagnosis of $\mathrm{HC}$ pain.

Abbreviations: $\mathrm{CH}$, cluster headache; $\mathrm{HC}$, hemicrania continua; $\mathrm{PH}$, paroxysmal hemicrania; SUNCT, short-lasting unilateral neuralgiform headache attacks with conjunctival injection and tearing; TTH, tension-type headache; NDPH, new daily persistent headache.

mild. ${ }^{41}$ 2) The duration and frequency of attacks are quite predictable in both $\mathrm{PH}$ and $\mathrm{CH}$ patients. The duration of attacks in $\mathrm{PH}$ and $\mathrm{CH}$ patients is $2-30$ and $15-180$ minutes, respectively. However, the duration of attack in $\mathrm{HC}$ patients is highly variable and many attacks are very prolonged (more than the upper limit of $\mathrm{CH}$ ). 3) Migrainous features are more common in $\mathrm{HC}$ patients than $\mathrm{CH}$ and $\mathrm{PH}$ patients.

If the physicians or the patients focus only on the exacerbation part and ignore continuous background pain, the diagnosis can be anything. ${ }^{6}$ As the duration of exacerbations can vary from a few seconds to a few days, the diagnosis may include neuralgias (especially supraorbital and trigeminal neuralgia), SUNCT/SUNA, PH, CH, migraine, TTH, etc.

Most of the exacerbations in $\mathrm{HC}$ last for a few hours. Exacerbations are usually throbbing in character and accompanied by migrainous features. In addition, we know that up to 71 patients may fulfill the criteria of migraine. ${ }^{6}$ Therefore, migraine is the most important differential diagnosis. Besides continuous background headaches, the presence of unilateral cranial autonomic features and restlessness or agitation during headache attacks favors HC over migraine. The age at the onset may also be helpful. The mean pooled age at the onset of $\mathrm{HC}$ was 40 years. The most common age at the onset of migraine is in the second and third decade of life. Therefore, before making a diagnosis of side-locked migraine, the presence of continuous background headache, presence of unilateral cranial autonomic features and agitation during an attack should be asked. In doubtful cases, a trial of indomethacin can be taken to see the response.

In Rossi et al's series, 32\% patients with $\mathrm{HC}$ fulfilled the diagnostic criteria for $\mathrm{CH}$ during the exacerbations. Differentiation of $\mathrm{HC}$ with $\mathrm{PH}$ or $\mathrm{CH}$ depends on two factors: 1) recognition of continuous background headache and 2) variable exacerbations. A few attacks in $\mathrm{CH}$ and $\mathrm{PH}$ patients may fall beyond the criteria prescribed by ICHD-3 $\beta$ for $\mathrm{CH}$ and $\mathrm{PH}$. However, if a patient with $\mathrm{CH}$ or with $\mathrm{PH}$ has several attacks beyond the defined duration in the criteria, think about a possibility of $\mathrm{HC}$.

On the contrary, if exacerbations are not severe or physicians focus only on continuous pain (ignoring exacerbation part), the differential diagnosis could be new daily persistent headache (NDPH), chronic tension-type headache (CTTH), atypical facial pain and various local pathologies. Side-locked NDPH with migrainous features may mimic HC. Approximately $11 \%-18 \%$ NDPH patients may be side locked. ${ }^{10} \mathrm{Up}$ to one-third of patients with NDPH may have migrainous feature. ${ }^{1}$ Mild autonomic features have also been reported with NDPH. If patients remember the exact onset of their headaches (first day of continuous headache), a possibility of NDPH is likely. In doubtful cases, a trial of indomethacin can be given to find out $\mathrm{HC}$.

Dental lesions, temporomandibular joint pathologies, sinus pathologies, neck pathologies and eye abnormalities may cause continuous pain in the trigeminal or surrounding distribution. All these structural pathologies are dealt with different experts of the medical field. Therefore, because of the wrong history or unawareness to $\mathrm{HC}$, a diagnosis of secondary headaches may be made. The patients may be subjected to even interventional surgeries for the incidental or unrelated pathologies.

\section{Approach to diagnose $\mathrm{HC}$}

The diagnosis of $\mathrm{HC}$ is made according to ICHD- $3 \beta$ criteria for HC (Table 5). A suspicion of HC and other TACs starts once one can see strictly unilateral headache (may be side shifting, but always unilateral). All TACs share some common clinical features. A mnemonic "3 As for unilateral headache" have been suggested to identify TACs. ${ }^{10} 3$ As include the following: 1) "anteriorly located" (orbital, frontal and temporal) pain, 2) "autonomic features" in the same area (ipsilateral) during attacks/exacerbations and 3) "agitation" during attacks 
or exacerbations. If all components of $3 \mathrm{As}$ are present, most likely it is one of the types of TACs. Even the presence of two As in the side-locked headache (anteriorly located pain with autonomic features or anteriorly located pain with agitation or agitation with autonomic features) is highly indicative of one of the forms of TACs.

Strictly unilateral headache is always a red flag sign. Therefore, a detailed history, investigations and appropriate investigation are a must in such patients (for details, the readers are encouraged to see a review on this topic). ${ }^{42}$ Once secondary causes are ruled out, we can diagnose primary TACs.

All TACs are episodic, except HC. Therefore, first of all, patients should be asked for the presence of continuous background headache. The patients themselves may not volunteer about it. As we know, the memory for pain is better for severe and the recent attacks. Therefore, a few patients, even on asking, may deny the presence of continuous headache. However, the patients with $\mathrm{HC}$ will have some form of headache even at the time of reporting to physicians. So, you can ask "Do you have headache right now". If the answer is "yes", it can be presumed that the patients may have continuous background headache. After saying "yes", many patients accept such mild continuous type of headaches in the past or between two attacks. Even if there is any doubt, one can wait for a few days to see prospectively whether there is continuous pain. Therapeutic response to indomethacin will confirm the diagnosis.

\section{Diagnosis by management}

Response to indomethacin is a must for HC. Oral indomethacin should be started to see the response. Intramuscular indomethacin 50-100 mg (INDOTEST) has been suggested as a diagnostic test for $\mathrm{HC}$ and $\mathrm{PH} .{ }^{43}$ Complete response usually occurs within 2 hours (mean 1.2 hours). Its role in atypical cases of HC may be very important. However, a few authors suggested that it can be a test of choice for chronic unilateral headache. ${ }^{44}$ Unfortunately, injectable indomethacin is not routinely available in every part of the world. Therefore, a therapeutic oral trial must be performed.

\section{Management} Indomethacin

A "complete" response to indomethacin is as "sine qua non" for HC. It is usually started at a dose of $25 \mathrm{mg}$ three times a day (tid). The drug is gradually titrated ( $25 \mathrm{mg}$ tid every 3-5 days) up to $100 \mathrm{mg}$ tid or until the patient gets complete relief. ${ }^{29}$ The dose required ranges from 25 to $500 \mathrm{mg} /$ day. ${ }^{6,14}$
The mean indomethacin dose varies between 94 and $176 \mathrm{mg} /$ day in various case series $^{6,8,14}$

It is said that response to indomethacin is immediate and complete. Several earlier case reports mentioned immediate response. ${ }^{44}$ However, this part has not been studied much. There is just one case series that mentioned the time interval between administrations of indomethacin and a complete response. ${ }^{29}$ Only $10 \%$ patients showed a complete response within 24 hours. A total of $43 \%$ patients showed complete response in a week. A few patients showed a marked response within a few days of starting treatment, but the complete response was noted only after 4 weeks. ${ }^{29,45}$ In a series of 39 patients reported by Cittadini and Goadsby, at least 15 patients received $\geq 225 \mathrm{mg}$ indomethacin. This dose (after titration) must have been given over 6-10 days. Therefore, we can presume that a large number of patients took more than 1 week to show complete response. All chronic painful conditions, including chronic headache, produce significant morphological changes in the pain matrix. ${ }^{46}$ Therefore, any chronic pain syndrome may lead to incomplete or delayed response to a specific drug. Therefore, HC with a very long history may take more time to show a complete response. ${ }^{46}$

A long-term follow-up study on 16 patients with $\mathrm{HC}$ suggests that $\sim 60 \%$ patients with $\mathrm{HC}$ may require a lower dose of indomethacin with the passage of time. ${ }^{47}$ Moreover, $15 \%$ patients may have relapsing-remission course. Therefore, a gradual reduction in the dose is recommended every 3-6 months. ${ }^{29}$ Dose reduction should be performed by $25 \mathrm{mg}$ every 3 days, until either the pain reappears or the patient gets completely off indomethacin. In this way, we can find out the remission phase of the patient or the lowest possible dose for a particular patient. There are a few case reports where HC symptoms remained controlled with $25 \mathrm{mg}$ daily or $25 \mathrm{mg}$ every alternate day. A sign of tolerance (tachyphylaxis) to indomethacin has not been reported in patients with $\mathrm{HC}$.

Skipping of the drug leads to an immediate appearance of the symptoms. This is also a very characteristic feature of HC. Antonaci and Sjaastad ${ }^{44}$ suggested that its diagnostic value (i.e., reappearance of headache after skipping of indomethacin) is stronger than INDOTEST itself.

\section{Alternative drugs for $\mathrm{HC}$}

Indomethacin is not a very safe drug for long-term use. Incidence and prevalence of indomethacin-related side effects in patients with $\mathrm{HC}$ vary between $20 \%$ and $75 \% .^{14,48}$ Various drugs and other interventions have been tried in patients who developed various indomethacin-related side effects. 
Table 8 Drugs other than indomethacin producing complete response in patients with $\mathrm{HC}$

\begin{tabular}{lll}
\hline Drugs & $\begin{array}{l}\text { Number of } \\
\text { patients }\end{array}$ & $\begin{array}{l}\text { Effective dose } \\
\text { (mg/day) }\end{array}$ \\
\hline Topiramate $^{14,20,28,29,31,48,101,102}$ & 16 & $100-200$ \\
Cyclooxygenase-2 inhibitors $^{\text {Rofecoxib } 11,37,39,103,104,105}$ & 15 & \\
Celecoxib $^{103,106}$ & 8 & $50-100$ \\
Corticosteroid (MPS) $^{14,29,107}$ & 7 & $200-600$ \\
Ibuprofen $^{29,25,108}$ & 14 & Oral-injectable \\
ASA $^{5,8}$ & 9 & $600-2400$ \\
Gabapentine $^{28,109,110}$ & 8 & $1400-2800$ \\
Melatonin $^{49,11-113}$ & 7 & $900-3600$ \\
Piroxicam derivative $^{23,28,114}$ & 6 & $6-9$ \\
Amitriptyline $^{28}$ & 6 & $20-60$ \\
Acemethacin $^{115}$ & 6 & $25-75$ \\
Verapamil $^{100,116}$ & 3 & 90 \\
Methysergide $^{14}$ & 2 & 120 \\
Nimesulide $^{11}$ & 1 & $*$ \\
\hline Notes: & 1 & $*$ \\
\hline
\end{tabular}

Notes: *Dosing details not available.

Abbreviations: ASA, acetyl salicylic acid; HC, hemicrania continua; MPS, methylprednisolone.

Table 8 summarizes the various alternative drugs used in HC patients. Various drugs have been found effective in case reports or open-label studies. The COX-2 inhibitors (celecoxib and rofecoxib,), piroxicam derivative and topiramate are the main drugs found to be effective in patients with HC. However, the effects of all these drugs are not uniform and consistent in each patient. It is difficult to predict which patient will respond to these drugs.

However, celecoxib and rofecoxib should be used with great precaution because of the increased risk of vascular events (myocardial infarction and strokes). Glaucoma, renal stones and depression are some problematic side effects with topiramate, and patients should be monitored for it. Melatonin can also be an option in indomethacin-tolerant patients. In a few patients, it may produce complete relief of pain. However, in other patients, addition of melatonin may allow $45 \%$ patients to reduce the dose of indomethacin. ${ }^{49}$

Table 8 included only those cases where response was either complete or excellent. However, there are several cases in the literature where these drugs were partially effective. Apart from these drugs, there are several other drugs (such as lamotrigine, lithium, naproxen and paracetamol with caffeine) that have provided marked (although partial) effect on some patients with HC. It can also be tried before subjecting the patient for interventional therapies.

We know that the reappearance of headache after skipping of indomethacin is a stronger clinical characteristic of HC. Therefore, immediate reappearance of $\mathrm{HC}$ will occur even with these effective drugs. A large number of patients with $\mathrm{HC}$ may receive these drugs unknowingly (without a correct diagnosis of HC). In clinical practice, we note several patients with strictly unilateral headaches who complain "they got a response as long as the drugs are continued". They may further say "headaches reappear immediately when they stop taking effective drugs". A possibility of HC is here, as no other headache reappears so fast on withdrawal of the effective drugs.

\section{Surgical interventions}

Several surgical approaches have been tried in patients with $\mathrm{HC}$ who could not tolerate indomethacin for a long term.

\section{Peripheral nerve block}

In earlier observations, there was no positive influence of nerve block in $\mathrm{HC}$ patients. There was only partial response to supraorbital nerve (SON) in a few patients in Antonaci et al's ${ }^{50}$ series. Only one patient (out of seven) showed complete response in Afridi et al' $\mathrm{s}^{51}$ series. In Cittadini and Goadsby's series, nerve block was performed in greater occipital nerve in 23 patients. Approximately one-third responded to greater occipital nerve (GON) injection. ${ }^{14}$

Recently, Guerrero et al ${ }^{13}$ reported nine patients with $\mathrm{HC}$ who received GON, SON, trochlear nerve or a combination of SON and GON blocks. Each patient had some tenderness over the represented peripheral nerves. Injections were chosen based on the tenderness. Five patients showed a complete response, while the rest had a partial response. The response started immediately after the block and persisted from 2 to 10 months. Repetition of blocks resulted in prolonged effects. The authors suggested that peripheral nerve block will be more effective if local tenderness is considered before the block.

\section{Sphenopalatine ganglion (SPG) block}

Very recently, Androulakis et a ${ }^{52}$ have shown an effect of repetitive blocks of SPG. Initially, it was performed twice per week. This was followed by maintenance treatment every 4-5 weeks. It produced significant (not complete) improvement on each occasion.

\section{Radiofrequency ablation}

Beams et $\mathrm{al}^{53}$ have demonstrated positive effects of radiofrequency ablation of the $\mathrm{C} 2$ ventral ramus (one case), $\mathrm{C} 2$ dorsal root ganglion (two cases) and SPG (one case). The response after each radiofrequency procedure was long lasting and it persisted from 1 to 2.5 years. Weyker et al ${ }^{54}$ used radiofrequency ablation of the SON in three patients 
with HC. Radiofrequency ablation showed complete relief of headache at 7-12-month follow-up.

\section{Occipital nerve stimulation (ONS)}

ONS is an effective treatment for various intractable primary headache disorders. Schwedt et $\mathrm{al}^{55}$ first examined the role of ONS in a patient with HC. The patient had significant improvement in pain (although not complete). However, the patient had episodes of cranial autonomic manifestation without headache. Schwedt et $\mathrm{al}^{56}$ treated two more patients by ONS. There was a marked reduction in headache frequency and pain intensity. However, both patients developed complications that include stimulator lead migration and infection.

Burns et $\mathrm{al}^{57}$ treated six patients with a newer wireless stimulator device (Bion). In this crossover study design, the Bion was on for 3 months, off for the fourth month and on again during the long-term follow-up. Four patients reported substantial improvement $(80 \%-95 \%)$ and one noted a $30 \%$ improvement. The onset of the benefit was delayed by days to weeks, and the headaches did not recur for a similar period when the device was switched off. Recently, Miller et $\mathrm{al}^{58}$ treated 16 patients by ONS in an open-label prospective study. The mean monthly moderate-to-severe headache days fell by $48.9 \%$. A favorable response ( $>50 \%$ reduction in monthly moderate-to-severe headache days) was observed in $50 \%$ patients.

\section{Vagus nerve stimulation (VNS)}

Nesbitt et $\mathrm{a}^{59}$ and Eren et $\mathrm{a}^{60}$ assessed the effect noninvasive VNS device in patients with HC. The patients were asked to stimulate the left vagus nerve in the neck with a transcutaneous vagus nerve stimulator. There was a reduction in pain intensity immediately after the stimulation in all three patients. Some more observations are required before it could be suggested for $\mathrm{HC}$.

\section{Botulinum toxin}

There are a total of three case reports or series in the literature. ${ }^{61-63}$ In the first case, the patient showed marked improvement (not complete) in headache days by trimestral injections. However, episodes of cranial autonomic occurred even in the absence of pain. ${ }^{61}$ Khalil and Ahmed ${ }^{62}$ reported another patient with $\mathrm{HC}$, where the response was complete that persisted for $\sim 10-12$ weeks. Recently, Miller et $\mathrm{al}^{63}$ reported nine patients with $\mathrm{HC}$ who were treated with multiple sessions of onabotulinumtoxin A injection. Five subjects had a response of $\geq 50 \%$ reduction in moderate-to-severe headache days to mild headache days or pain-free state. The median reduction in total headache days was $90 \%$ and in moderate-to-severe headache days $80 \%$. The median duration of response of the five responders was 11 weeks. However, more studies are necessary before it could be recommended for HC.

\section{Future perspective}

Wide heterogeneity in clinical features and marked variability in therapeutic responses to various drugs in patients with HC suggest that several things are still to be explored. There are no uniformly accepted diagnostic criteria for $\mathrm{HC}$. No case studies have yet been published based on the recent ICHD-3 $\beta$ criteria (2013).

Migraine and TTH have alternative criteria in the appendix section of ICHD-3 $\beta$. There is a need for alternative diagnostic criteria even for the most controversial primary headache disorder ( $\mathrm{HC}$ ), so that its various aspects can be explored in different clinical and epidemiological settings. We have suggested more accommodating type criteria for appendix section. ${ }^{14}$

Cranial autonomic features, agitation and response to indomethacin are three important issues in the diagnostic criteria. Agitation was not the part of earlier criteria. It was first included in Cittadini and Goadsby criteria (2010) ${ }^{14}$ and later on in Prakash and Golwala criteria (2012) ${ }^{29}$ and now in ICHD-3 $\beta$ criteria (2013). ${ }^{1}$ In ICHD-3 $\beta$ criteria, agitation and cranial autonomic features have been put together and only one of these two features is required for diagnosis purpose.

The most debated issue is about the response to indomethacin. It was "not a must" in the Goadsby and Lipton criteria (1997). ${ }^{64}$ However, since ICHD-2 (2004), it is a "must" feature. ${ }^{4}$ Several cases of indomethacin-resistant $\mathrm{HC}$ had been published before 2004. However, there was a sudden quietness in the reporting of indomethacin-resistant $\mathrm{HC}$ in the literature after 2004 till Marmura et al ${ }^{65}$ and Prakash and Golwala ${ }^{29}$ reported several cases with HC phenotype but with no or minimal response. In a review, we noted underreporting (or no reports) of indomethacin-resistant HC. ${ }^{66}$ There are several authors who in principle accept a possibility of indomethacin-resistant HC. ${ }^{66}$ Moreover, the word "complete" is also debatable. There are several cases with marked/excellent response to indomethacin. But it cannot be classified as $\mathrm{HC}$ according to current criteria. Chronic painful conditions, including chronic daily headache, are known for their refractoriness (or partial response to various drugs).

We suggested (Prakash-Golwala criteria; Table 9) that the presence of any two of the following is enough to make a diagnosis of $\mathrm{HC}$ : 1) cranial autonomic features, 2) a sense 
Table 9 Prakash and Golwala criteria (modified) for HC

\begin{tabular}{l} 
A Headache for $>\mathbf{3}$ months fulfilling criteria B-D \\
\hline B All the following characteristics: \\
I Unilateral orbital, supraorbital or temporal pain without side shift \\
2 Daily and continuous, without pain-free periods \\
3 Moderate intensity, but with exacerbations of severe pain \\
C At least two of the following: \\
I At least one of the following autonomic features occurs during \\
exacerbations and ipsilateral to the side of pain: \\
a) Conjunctival injection and/or lacrimation \\
b) Nasal congestion and/or rhinorrhea \\
c) Eyelid edema \\
d) Forehead and facial sweating \\
e) Forehead and facial flushing \\
f) Sensation of fullness in the ear \\
g) Miosis and/or ptosis \\
h) Feeling of sand in eye
\end{tabular}

2 A sense of restlessness or agitation, or aggravation of the pain by movement

3 Headache resolves or greatly improves to therapeutic doses of indomethacin

D Not better accounted for by another ICHD-3 $\beta$ diagnosis

Note: Copyright @2012. Sage Journals. Adapted from Prakash S, Golwala P. A proposal for revision of hemicrania continua diagnostic criteria based on critical analysis of 62 patients. Cephalalgia. 20I2;32(I I):860-868. ${ }^{29}$

Abbreviations: HC, hemicrania continua; ICHD-3 $\beta$, International Classification of Headache Disorder, third edition.

of restlessness during exacerbations and 3) a response to indomethacin.

ICHD-3 $\beta$ criteria for $\mathrm{HC}$ did not mention the site of pain. As sites of pain in $\mathrm{HC}$ are comparable to that of $\mathrm{CH}, \mathrm{PH}$ and SUNCT/SUNA, it should be included even for HC.

As suggested earlier, feeling of foreign body sensation in the eye (or sand in eye sensation or itching eye) is very specific and a common CAS. We suggest to include it in the diagnostic criteria of $\mathrm{HC}$ as a part of CAS.

We think that current ICHD-3 $\beta$ criteria are still restrictive. As clinical features, therapeutic options and many other aspects are still to be defined in patients with $\mathrm{HC}$, we suggest more accommodating and broader criteria (at least in the appendix section of ICHD-3 $\beta$; Table 9). Broader criteria will inspire clinician/researchers to study such type of headaches, and it would provide a broader view of $\mathrm{HC}$ and $\mathrm{HC}$-like headaches. We suggest large prospective or retrospective studies from multiple centers to validate the different criteria proposed for $\mathrm{HC}$.

\section{Acknowledgment}

No grant or support was required for this review.

\section{Author contributions}

SP and PP were involved in the conception and design of the review. SP and PP were involved in the acquisition of data. SP was involved in the manuscript preparation. PP was involved in revising the draft for intellectual content. Both authors contributed toward data analysis, drafting and revising the paper and agree to be accountable for all aspects of the work.

\section{Disclosure}

The authors report no conflicts of interest in this work.

\section{References}

1. Headache Classification Committee of the International Headache Society (IHS). The International Classification of Headache Disorders, 3rd (beta version). Cephalalgia. 2013;33(9):629-808.

2. Medina JL, Diamond S. Cluster headache variant: spectrum of a new headache syndrome. Arch Neurol. 1981;38(1):705-709.

3. Sjaastad O, Spierings EL. Hemicrania continua: another headache absolutely responsive to indomethacin. Cephalalgia. 1984;4:65-70.

4. Headache Classification Subcommittee of the International Headache Society. The International Classification of Headache Disorders, 2nd ed. Cephalalgia. 2004;24(Suppl 1):1-160.

5. Bordini C, Antonaci F, Stovner LJ, et al. "Hemicrania continua": a clinical review. Headache. 1991;31(1):20-26.

6. Peres M, Silberstein SD, Nahmias S. Hemicrania continua is not that rare. Neurology. 2001;57(6):948-951.

7. Wheeler S. Clinical spectrum of hemicrania continua. Neurology. 2000;54:A422. Abstract.

8. Espada F, Escalza I, Morales-Asin F, Navas I, Inignez C, Mauri JA. Hemicrania continua: nine new cases. Cephalalgia. 1999;19:442. Abstract.

9. Sjaastad O, Bakketeig LS. The rare, unilateral headaches. Vaga study of headache epidemiology. J Headache Pain. 2007;8(1):19-27.

10. Prakash S, Rathore C. Side-locked headaches: an algorithm-based approach. J Headache Pain. 2016;17(1):95.

11. Rossi P, Faroni J, Tassorelli C, Nappi G. Diagnostic delay and suboptimal management in a referral population with hemicranias continua. Headache. 2009;49(2):227-234.

12. Cortijo E, Guerrero-Peral ÁL, Herrero-Velázquez S, et al. Hemicrania continua: characteristics and therapeutic experience in a series of 36 patients. Rev Neurol. 2012;55(5):270-278.

13. Weatherall MW, Bahra A. Familial hemicrania continua. Cephalalgia. 2011;31(2):245-249.

14. Cittadini E, Goadsby PJ. Hemicrania continua: a clinical study of 39 patients with diagnostic implications. Brain. 2010;133(Pt 7):1973-1986.

15. Newman LC, Lipton RB, Russell M, Solomon S. Hemicrania continua: attacks may alternate sides. Headache. 1992;32(5):237-238.

16. Newman LC, Spears RC, Lay CL. Hemicrania continua: a third case in which attacks alternate sides. Headache. 2004;44(8):821-823.

17. Baldacci F, Nuti A, Cafforio G, et al. INDOTEST' in atypical hemicrania continua. Cephalalgia. 2008;28(3):300-301.

18. Marano E, Giampiero V, Gennaro DR, di Stasio E, Bonusa S, Sorge F. Hemicrania continua: a possible case with alternating sides. Cephalalgia. 1994;14(4):307-308.

19. Peres MF, Masruha MR, Young WB. Side-shifting hemicrania continua with aura (migraine with aura with autonomic symptoms responsive to indomethacin?). Cephalalgia. 2006;26(8):917-919.

20. Matharu MS, Bradbury P, Swash M. Hemicrania continua: side alternation and response to topiramate. Cephalalgia. 2006;26(3):341-344.

21. Pasquier F, Leys D, Petit H. Hemicrania continua: the first bilateral case? Cephalalgia. 1987;7(3):169-170.

22. Iordanidis T, Sjaastad O. Hemicrania continua: a case report. Cephalalgia. 1989;9(4):301-303.

23. Trucco M, Antonaci F, Sandrini G. Hemicrania continua: a case responsive to piroxicam-beta-cyclodextrin. Headache. 1992;32(1):39-40.

24. Southerland AM, Login IS. Rigorously defined hemicrania continua presenting bilaterally. Cephalalgia. 2011;31(14):1490-1492. 
25. Newman LC, Lipton RB, Solomon S. Hemicrania continua: ten new cases and a review of the literature. Neurology. 1994;44(11):2111-2114.

26. Benítez-Rivero S, González-Oria C, Gómez-Caravaca T, Bernal Sánchez-Arjona M, Jiménez-Hernández MD. Hemicrania continua and paroxysmal hemicrania: clinical and therapeutic characteristics in a series of 23 patients. Rev Neurol. 2014;59(8):337-344.

27. Peres M, Stiles MA, Oshinsky M, Rozen TD. Remitting form of hemicrania continua with seasonal pattern. Headache. 2001;41(6):592-594.

28. de Moura LM, Bezerra JM, Fleming NR. Treatment of hemicranias continua: case series and literature review. Rev Bras Anestesiol. 2012;62(2):173-187.

29. Prakash S, Golwala P. A proposal for revision of hemicrania continua diagnostic criteria based on critical analysis of 62 patients. Cephalalgia. 2012;32(11):860-868.

30. Peres M, Slow HC, Rozen TD. Hemicrania continua with aura. Cephalalgia. 2002;22(3):246-248.

31. Fantini J, Koscica N, Zorzon M, Belluzzo M, Granato A. Hemicrania continua with visual aura successfully treated with a combination of indomethacin and topiramate. Neurol Sci. 2015;36(4):643-644.

32. Kuhn J, Kuhn KF, Cooper-Mahkorn D, Bewermeyer H. Remitting form of hemicrania continua: two new cases exhibiting one unusual autonomic feature. Headache. 2005;45(6):759-762.

33. Prakash S, Shah ND. Pure menstrual hemicrania continua: does it exist? A case report. Cephalalgia. 2010;30(5):631-633.

34. Guerrero ÁL, Herrero-Velázquez S, Peñas ML, et al. Peripheral nerve blocks: a therapeutic alternative for hemicrania continua. Cephalalgia. 2012;32(6):505-508.

35. Finkel AG, Yerry JA, Klaric JS, Ivins BJ, Scher A, Choi YS. Headache in military service members with a history of mild traumatic brain injury: a cohort study of diagnosis and classification. Cephalalgia. 2017;37(6):548-559.

36. Lay CL, Newman LC. Posttraumatic hemicrania continua. Headache. 1999;39(4):275-279.

37. Bigal ME, Tepper SJ, Sheftell FD, Rapoport AM. Hemicrania continua: a report of ten new cases. Arq Neuropsiquiatr. 2002;60(3-B): 695-698.

38. Cosentino G, Fierro B, Puma AR, Talamanca S, Brighina F. Different forms of trigeminal autonomic cephalalgias in the same patient: description of a case. J Headache Pain. 2010;11(3):281-284.

39. Müller KI, Bekkelund SI. Hemicrania continua changed to chronic paroxysmal hemicrania after treatment with cyclooxygenase- 2 inhibitor. Headache. 2011;51(2):300-305

40. Rozen TD. Indomethacin-responsive TACs (paroxysmal hemicrania, hemicrania continua, and LASH): further proof of a distinct spectrum of headache disorders. Headache. 2013;53(9):1499-1500.

41. Marmura MJ, Young WB. Interictal pain in primary headache syndromes. Curr Pain Headache Rep. 2012;16(2):170-174.

42. Prakash S, Shah ND, Soni RK. Secondary hemicranias continua: case reports and a literature review. J Neurol Sci. 2009;280(1-2) 29-34.

43. Antonaci F, Pareja JA, Caminero AB, Sjaastad O. Chronic paroxysmal hemicrania and hemicrania continua. Parenteral indomethacin: the 'indotest'. Headache. 1998;38(2):122-128.

44. Antonaci F, Sjaastad O. Hemicrania continua. Handb Clin Neurol. 2010;97(third series):483-487.

45. Prakash S, Shah ND. Delayed response of indomethacin in patients with hemicrania continua: real or phantom headache? Cephalalgia. 2010;30(3):375-379.

46. Prakash S, Golwala P. Phantom headache: pain-memory-emotion hypothesis for chronic daily headache? J Headache Pain. 2011;12(3): 281-286.

47. Pareja JA, Caminero AB, Franco E, et al. Dose, efficacy, and tolerability of long-term indomethacin treatment for chronic paroxysmal hemicrania and hemicrania continua. Cephalalgia. 2001;21(9):906-910.

48. Prakash S, Husain M, Sureka D, Shah N, Shah N. Is there need to search for alternatives to indomethacin for hemicrania continua? Case reports and a review. J Neurol Sci. 2009;277(1-2):187-190.
49. Rozen TD. How effective is melatonin as a preventive treatment for hemicrania continua? A clinic-based study. Headache. 2015;55(3): 430-436.

50. Antonaci F, Pareja JA, Caminero AB, Sjaastad O. Chronic paroxysmal hemicrania and hemicrania continua: anaesthetic blockades of pericranial nerves. Funct Neurol. 1997;12(1):11-15.

51. Afridi SK, Shields KG, Bhola R, Goadsby PJ. Greater occipital nerve injection in primary headache syndromes--prolonged effects from a single injection. Pain. 2006;122(1-2):126-129.

52. Androulakis XM, Krebs KA, Ashkenazi A. Hemicrania continua may respond to repetitive sphenopalatine ganglion block: a case report. Headache. 2016;56(3):573-579.

53. Beams JL, Kline MT, Rozen TD. Treatment of hemicrania continua with radiofrequency ablation and long-term follow-up. Cephalalgia. 2015;35(13):1208-1213.

54. Weyker P, Webb C, Mathew L. Radiofrequency ablation of the supraorbital nerve in the treatment algorithm of hemicrania continua. Pain Physician. 2012;15(5):E719-E724.

55. Schwedt TJ, Dodick DW, Trentman TL, et al. Occipital nerve stimulation for chronic cluster headache and hemicrania continua: pain relief and persistence of autonomic features. Cephalalgia. 2006;26(8):1025-1027.

56. Schwedt TJ, Dodick DW, Hentz J, Trentman TL, Zimmerman RS. Occipital nerve stimulation for chronic headache-long-term safety and efficacy. Cephalalgia. 2007;27(2):153-157.

57. Burns B, Watkins L, Goadsby P. Treatment of hemicrania continua by occipital nerve stimulation with a bion device: long-term follow-up of a crossover study. Lancet Neurol. 2008;7(11):1001-1012.

58. Miller S, Watkins L, Matharu MS. Treatment of intractable hemicrania continua by occipital nerve stimulation. J Neurol Neurosurg Psychiatry. Epub 2017 Mar 2. doi: 10.1136/jnnp-2017-315747.

59. Nesbitt A, Marin J, Goadsby P. Treatment of hemicrania continua by non-invasive vagus nerve stimulation in 2 patients previously treated with occipital nerve stimulation. J Headache Pain. 2013;14(Suppl 1):230.

60. Eren O, Straube A, Schöberl F, Schankin C. Hemicrania continua: beneficial effect of non-invasive vagus nerve stimulation in a patient with a contraindication for indomethacin. Headache. 2017;57(2):298-301.

61. Garza I, Cutrer F. Pain relief and persistence of dysautonomic features in a patient with hemicrania continua responsive to botulinum toxin type A. Cephalalgia. 2010;30(4):500-503.

62. Khalil M, Ahmed F. Hemicrania continua responsive to botulinum toxin type A: a case report. Headache. 2013;53(5):831-833.

63. Miller S, Correia F, Lagrata S, Matharu MS. OnabotulinumtoxinA for hemicrania continua: open label experience in 9 patients. $J$ Headache Pain. 2015;16:19.

64. Goadsby PJ, Lipton RB. A review of paroxysmal hemicranias, SUNCT syndrome and other short-lasting headaches with autonomic feature, including new cases. Brain. 1997;120(Pt 1):193-209.

65. Marmura MJ, Silberstein SD, Gupta M. Hemicrania continua: who responds to indomethacin? Cephalalgia. 2009;29(3):300-307.

66. Prakash S, Shah ND, Bhanvadia RJ. Hemicrania continua unresponsive or partially responsive to indomethacin: does it exist? A diagnostic and therapeutic dilemma. J Headache Pain. 2009;10(1):59-63.

67. Prakash S, Rathore C, Makwana P, Dave A. A cross-sectional clinicbased study in patients with side-locked unilateral headache and facial pain. Headache. 2016;56(7):1183-1193.

68. Ramón C, Mauri G, Vega J, Rico M, Para M, Pascual J. Diagnostic distribution of 100 unilateral, side-locked headaches consulting a specialized clinic. Eur Neurol. 2013;69(5):289-291.

69. Evans RW, Lay CL. Posttraumatic hemicrania continua? Headache. 2000;40(9):761-762.

70. Wheeler SD. Hemicrania continua in African Americans. J Natl Med Assoc. 2002;94(10):901-907.

71. Schwedt TJ, Dodick DW, Trentman TL, Zimmerman RS. Occipital nerve stimulation for chronic cluster headache and hemicrania continua: pain relief and persistence of autonomic features. Cephalalgia. 2006;26(8):1025-1027. 
72. Gantenbein AR, Sarikaya H, Riederer F, Goadsby PY. Postoperative hemicranias continua like headache - a case series. J Headache Pain. 2015;16:41.

73. Brilla R, Pawlowski M, Evers S. Hemicrania continua in carotid artery dissection - symptomatic cases or linked pathophysiology? Cephalalgia. 333102416686346 . Epub 2017 Jan 1. doi: 10.1177/0333102416686346.

74. Mathew T, Badachi S, Sarma GR, Nadig R. Cerebral venous thrombosis masquerading as hemicrania continua. Neurol India. 2014;62(5):556-557.

75. Wang SJ, Hung CW, Fuh JL, Lirng JF, Hwu CM. Cranial autonomic symptoms in patients with pituitary adenoma presenting with headaches. Acta Neurol Taiwan. 2009;18(2):104-112.

76. Mainardi F, Zanchin G, Maggioni F. Hemicrania continua-like headache related to transdermal nitroglycerine therapy. Headache. 2017;57(3):494-496

77. Zhang Y, Wang D, He Z, Wu Q, Zhou J. Hemicrania continua-like headache secondary to nasopharyngeal carcinoma: a case report. Cephalalgia. Epub 2016 June 10.

78. DeLange JM, Robertson CE, Krecke KN, Garza I. A case report of hemicrania continua-like headache due to ipsilateral inflammatory orbital pseudotumor. Headache. 2014;54(9):1541-1542.

79. Prakash S, Dholakia SY. Hemicrania continua-like headache with leprosy: casual or causal association? Headache. 2008;48(7):1132-1134.

80. Ferreira KS, Freitas DJ, Speciali JG. Is there a relation between hemicrania continua and leprosy? Indian J Lepr. 2012;84(4):317-320.

81. Eross EJ, Swanson JW, Dodick DW. Hemicrania continua: an indomethacin responsive case with an underlying malignant etiology. Headache. 2002;42(6):527-529.

82. Evans RW. Hemicrania continua-like headache due to nonmetastatic lung cancer - a vagal cephalalgia. Headache. 2007;47(9):1349-1351.

83. Robbins MS, Grosberg BM. Hemicrania continua-like headache from metastatic lung cancer. Headache. 2010;50(6):1055-1056.

84. Totzeck A, Diener HC, Gaul C. Concomitant occurrence of different trigeminal autonomic cephalalgias: a case series and review of the literature. Cephalalgia. 2014;34(3):231-235.

85. Lisotto C, Mainardi F, Maggioni F, Zanchin G. Hemicrania continua with contralateral episodic cluster headache: a case report. Cephalalgia. 2003;23(9):929-930.

86. Saito Y, Manaka S, Kimura S. Coexistence of cluster headache and hemicrania continua: a case report. Rinsho Shinkeigaku. 2005;45(3): 250-252.

87. Robbins MS, Grosberg BM, Lipton RB. Coexisting trigeminal autonomic cephalalgias and hemicrania continua. Headache. 2010;50(3): 489-496.

88. Evers S, Bahra A, Goadsby PJ. Coincidence of familial hemiplegic migraine and hemicrania continua? A case report. Cephalalgia. 1999;19(5):533-535.

89. Allena M, Tassorelli C, Sances G, et al. Is hemicrania continua a single entity or the association of two headache forms? Considerations from a case report. Headache. 2010;50(5):877-881.

90. Cuadrado ML, Porta-Etessam J, Pareja JA, Matías-Guiu J. Hemicrania continua responsive to trochlear injection of corticosteroids. Cephalalgia. 2010;30(3):373-374.

91. Prakash S, Rathore C. Two cases of hemicrania continua-trigeminal neuralgia syndrome: expanding the spectrum of trigeminal autonomic cephalalgia-Tic (TAC-TIC) syndrome. Headache. 2017;57(3): 472-477.

92. Prakash $\mathrm{S}$. Hyper insulinemia in an hemicrania continua patient with sexual headache: hypothesizing the basis for this unusual association. Neurol India. 2010;58(4):642-644.

93. Porzukowiak TR. Raeder paratrigeminal neuralgia evolving to hemicrania continua. Optom Vis Sci. 2015;92(4 Suppl 1):S81-S87.
94. Koutsis G, Andreadou E, Matsi S, Evangelopoulos ME, Sfagos C. Benign Raeder syndrome evolving into indomethacin-responsive hemicranial headache. Headache. 2008;48(10):1534-1536.

95. Castellanos-Pinedo F, Zurdo M, Martínez-Acebes E. Hemicrania continua evolving from episodic paroxysmal hemicrania. Cephalalgia. 2006;26(9):1143-1145.

76. Terlizzi R, Cevoli S, Nicodemo M, Pierangeli G, Grimaldi D, Cortelli P. A case of strictly unilateral migraine without aura transformed in an episodic hemicrania continua. Neurol Sci. 2011;32(1):169-170.

97. Palmieri A, Mainardi F, Maggioni F, Dainese F, Zanchin G. Hemicrania continua evolving from migraine with aura: clinical evidence of a possible correlation between two forms of primary headache. Cephalalgia. 2004;24(11):1007-1008.

98. Lambru G, Castellini P, Bini A, Evangelista A, Manzoni GC, Torelli P. Hemicrania continua evolving from cluster headache responsive to valproic acid. Headache. 2008;48(9):1374-1376.

99. Centonze V, Attolini E, Campanozzi F, et al. "Hemicrania continua": a new clinical entity or a further development from cluster headache? A case report. Cephalalgia. 1987;7(3):167-168.

100. Rozen TD. Verapamil-responsive hemicrania continua in a patient with episodic cluster headache. Cephalalgia. 2006;26(3):351-353.

101. Camarda C, Camarda R, Monastero R. Chronic paroxysmal hemicrania and hemicrania continua: two case reports. Clin Neurol Neurosurg. 2008;110(1):88-90.

102. Brighina F, Palermo A, Consentino G, Fierro B. Prophylaxis of hemicrania continua: two new cases effectively treated with topiramate. Headache. 2007;47(3):441-443.

103. Peres MFP, Silberstein SD. Hemicrania continua responds to cyclooxygenase-2 inhibitors. Headache. 2002;42(6):530-531.

104. Peres MFP, Zukerman E. Hemicrania continua responsive to rofecoxib. Cephalalgia. 2000;20(2):130-131.

105. Wheeler SD. Rofecoxib-responsive hemicrania continua. Headache. 2000;40:436-437.

106. Porta-Etessam J, Cuadrado M, Rodriguez-Gomez O, Garcia-Ptacek S, Valencia C. Are cox-2 drugs the second line option in indomethacin responsive headaches? J Headache Pain. 2010;11(5):405-407.

107. Prakash S, Brahmbhatt KJ, Chwda NT, Tandon N. Hemicrania continua responsive to intravenous methylprednisolone. Headache. 2009;49(4):604-607.

108. Kumar KL, Bordiuk JD. Hemicrania continua: a therapeutic dilemma. Headache. 1991;31(5):345.

109. Mariano da Silva H, Alcantara MC, Bordini CA, Speciali JG. Strictly unilateral headache reminiscent of hemicrania continua resistant to indomethacin but responsive to gabapentin. Cephalalgia. 2002;22(5):409-410.

110. Spears R. Is gabapentin an effective treatment choice for hemicranias continua? J Headache Pain. 2009;10(4):271-275.

111. Rozen TD. Melatonin responsive hemicrania continua. Headache. 2006;46(7):1203-1204.

112. Spears RC. Hemicrania continua: a case in which a patient experienced complete relief on melatonin. Headache. 2006;46(3):524-527.

113. Hollingworth M, Young TM. Melatonin responsive hemicrania continua in which indomethacin was associated with contralateral headache. Headache. 2014;54(5):916-919.

114. Sjaastad O, Antonaci F. A piroxicam derivative partly effective in chronic paroxysmal hemicrania and hemicrania continua. Headache. 1995;35(9):549-550.

115. Nicpoń KJ, Nicpoń KW, Jaroszuk-Nicpoń J. Prophylaxis of hemicrania continua: three cases effectively treated with acemethacin. Cephalalgia. 2011;31(5):625-627.

116. Rajabally YA, Jacob S. Hemicrania continua responsive to verapamil. Headache. 2005;45(8):1082-1083. 
The Journal of Pain Research is an international, peer reviewed, open access, online journal that welcomes laboratory and clinical findings in the fields of pain research and the prevention and management of pain. Original research, reviews, symposium reports, hypothesis formation and commentaries are all considered for publication
The manuscript management system is completely online and includes a very quick and fair peer-review system, which is all easy to use. Visit http://www.dovepress.com/testimonials.php to read real quotes from published authors.

Submit your manuscript here: https://www.dovepress.com/journal-of-pain-research-journal 